\title{
Enhancing Breastfeeding Through Healthcare Support: Results from a Focus Group Study of African American Mothers
}

\author{
Angela M. Johnson ${ }^{1} \cdot$ Rosalind Kirk $^{2} \cdot$ Alfreda Jordan Rooks ${ }^{1} \cdot$ Maria Muzik $^{2}$
}

Published online: 23 July 2016

(c) Springer Science+Business Media New York 2016

\begin{abstract}
Objectives To explore African American women's breastfeeding thoughts, attitudes, and experiences with healthcare professionals and subsequent influences on their breastfeeding interest and behavior. Insight was also sought about the most effective practices to provide breastfeeding support to African American women. Methods Thirty-eight pregnant or lactating African American women and racially diverse health professionals were recruited and participated in one of six membership specific focus groups in the metro Detroit area. An experienced focus group facilitator who was African American woman served as the primary group facilitator, using a semi-structured guide to discussions. Focus groups explored perceptions of personal and professional roles and behaviors that support African American women's breastfeeding behavior. Discussions were digitally recorded and audiotapes were transcribed. Thematic content analysis was conducted in combination with a review of field notes. Results Participants generally agreed that breastfeeding is the healthier feeding method but perceived that healthcare providers were not always fully supportive and sometimes discouraged breastfeeding. Non-breastfeeding mothers
\end{abstract}

Maria Muzik

muzik@med.umich.edu

1 Program for Multicultural Health, Department of Community Programs and Services, University of Michigan Health System, 2025 Traverwood Dr., Ann Arbor, MI 48105-2197, USA

2 Women and Infants Mental Health Program, Department of Psychiatry, Rachel Upjohn Building, 4250 Plymouth Rd, Ann Arbor, MI 48109, USA often expressed distrust of the information and recommendations given by healthcare providers and relied more on peers and relatives. Health professionals lacked information and skills to successfully engage African American women around breastfeeding. Conclusions for Practice Breastfeeding initiation and duration among African American mothers may increase when postpartum breastfeeding interventions address social and cultural challenges and when hospital breastfeeding support with the right professional lactation support, is void of unconscious bias and bridges hospital, community, peers, and family support. Professional lactation training for healthcare professionals who are in contact with expectant and new mothers and an increase in the number of IBCLC of color could help.

Keywords Breastfeeding - African American . Qualitative · Interventions · Peer support

\section{Significance}

It is well established that breastfeeding supports optimal maternal and child physical and mental health. It also provides important social and economic benefits for mothers and babies during the postpartum period. Despite the recent increase in overall rates, a persistent racial gap in breastfeeding behavior remains. African American mothers initiate and continue breastfeeding at far lower rates when compared to other racial and ethnic groups. This study reveals that the unique social, cultural, and historical perspectives of African American women may negatively impact their breastfeeding behavior and that health professionals can unwittingly struggle to provide effective acceptable breastfeeding support practices. 


\section{Introduction}

Breastfeeding provides innumerable health benefits for mothers and babies (Kramer et al. 2008) and thus is a critical part of optimum postpartum health and wellness. It remains the ideal food source for nutritional, physiological, immunological and developmental benefits (Horta and Victora 2013). Exclusive breastfeeding is internationally viewed as the "cornerstone of infant" health because it provides "essential, irreplaceable nutrition for child growth and development" (Who/Unicef 2012). There are also large societal health and economic benefits. A recent cost analysis of health savings from all pediatric diseases associated with breastfeeding estimated that if $90 \%$ of U.S. families complied with national policy recommendations to breastfeed exclusively for 6 months postpartum, the U.S. might save as much as $\$ 13$ billion per year and prevent over 911 deaths, primarily in infants (Bartick and Reinhold 2010). National Immunization Surveys for children born in 2012, showed that breastfeeding rates for Hispanic and Asian women met the Healthy People 2020 breastfeeding initiation target goal of $81.9 \%$; $82.4 \%$ Hispanic women breastfed and $83 \%$ of white women breastfed. However, breastfeeding initiation rates remained markedly lower among African American women at only $66 \%$ initiation (Centers for Disease Control and Prevention 2015). Consequently racial disparities in breastfeeding behavior persist, highlighting short and longer term postpartum health risks such as infectious disease, sudden infant death syndrome, obesity, and type 2 diabetes (Stuebe 2009) for African American women and children.

Access to postpartum breastfeeding support and protection is considered an issue of equity and social justice (Perez-Escamilla and Sellen 2015). These lower rates among African Americans set a poor life trajectory with a higher risk for poor postnatal health outcomes and possibly contributes to life-long health disparities (Spencer and Grassley 2012). Shorter maternity leaves, inflexible work environment for mothers returning to work postpartum (Conrad 2006; McCarter-Spaulding et al. 2011; Li et al. 2004), lack of breastfeeding role models, (Bentley et al. 2003; Gayle Shipp and Michigan 2015), chronic maternal health conditions, (Johnson 2010), and stress due to racism and discrimination are known breastfeeding barriers for African American women (Johnson et al. 2015b).

Previous research suggests that complex patterns of stress negatively impact maternal and child health outcomes as early as the preconception period (Ramey et al. 2015) so healthcare providers who interact with mothers during the pre- and perinatal periods are critical actors within a multilevel systems approach to reduce breastfeeding inequities (Pérez-Escamilla et al. 2012).

\section{Current Healthcare Breastfeeding Policies and Practices}

Internationally, the World Health Organization recommends exclusive breastfeeding for the first 6 months of an infants' life (Organization, W. H 2001). US hospital practices implemented under the Baby Friendly Hospital Initiative (BHFI) reinforce the importance of hospital lactation support but may have limited impact on breastfeeding outcomes among African American women (Labbok 2013). First, although breastfeeding support protocol exists for healthcare professionals such as the Ten Steps to Successful Breastfeeding outlined in the BFHI (USA 2012) and has enjoyed worldwide adoption (Saadeh and Casanovas 2009), its' success in the United States is unimpressive (Saadeh 2012), particularly for African American women. The limited impact of BFHI for African American mothers is attributable to geographical locations of BFHI-designated hospitals that are not serving large numbers of African American patients (Centers for Disease Control and Prevention 2014; Merewood et al. 2005), thus making it uncertain that this policy may benefit African American women. Healthcare systems are too often said to be inconsistent and ambivalent (Labbok 2013) facilitating "passive barriers" that result from frequent "lack of recognition and support for breastfeeding among all patients" and "active barriers" such as "inattention to the importance of breastfeeding..., including the too-easy recommendation to stop breastfeeding for procedures when this is not warranted". (p. 16). This was supported by Demirci et al. (2013) who found that breastfeeding conversations between physicians and their patients are infrequent and too brief. Provisions made by the Affordable Care Act of 2010 may negatively impact breastfeeding among African American mothers for multiple reasons. First, the broad discretion afforded employers under ACA mandated rules for "break time" and pumping accommodations provisions have proven unenforceable thus far and likely still allow historical racist and classist attitudes to limit especially low-income women's ability to pump at work (and thus breastfeed). Secondly, African American women, still constrained and unable to breastfeed, may be re-stigmatized for not performing the optimum motherhood behavior of breastfeeding (Ehrenreich and Siebrase 2014).

Healthcare providers could help mothers and their babies establish and maintain and continued breastfeeding for 2 years or beyond, particularly, exclusive breastfeeding (Bentley et al. 2003; Jones et al. 2015; Gross et al. 2014) and have an opportunity to influence mothers' prenatal attitudes, and post-birth breastfeeding plans, but often fail to do so.

Current breastfeeding interventions are disjointed and fail to effectively address the unique and important social 
and cultural barriers experienced by African American women (Johnson et al. 2015b). First, current interventions provide some support for mothers, but tend to be singular, not cumulative and multilevel as suggested. Breastfeeding promotion should reflect socio-ecological perspective, occur simultaneously at several levels and at multiple points in time (Tiedje et al. 2002) to help ensure that mothers can initiate and maintain breastfeeding beyond their hospital stay. Like other health disparities, "social, cultural, economic, and physical factors surround the human experience and are recognized as the most significant determinants of health" (Porr et al. 2006). For example, a lack of African American lactation consultants in Michigan impacts African American women's ability to build effective breastfeeding support relationships and provide appropriate role models (Medicine 2013). Research also suggests that mothers need a comprehensive, multi-systems approach offering community-based lactation professionals, community and peer support to address social and personal breastfeeding barriers (Johnson et al. 2015a, b). Exploring the influence of healthcare provider support presents a critical opportunity to enhance breastfeeding behavior among African American mothers in ways that enhance their postpartum health and wellness.

As a consequence of these challenges, the objective of this study is to explore the perceived impact of healthcare providers' on breastfeeding intention and behavior among African American women and to discover potential strategies that optimize the supportive role that lactation professionals might play (Table 1).

\section{Methods}

The study met ethically high standards and was approved by the Human Subjects Institutional Review Board at the University of Michigan. This was part of a larger study to explore current perspectives on effective strategies that support African American mothers' breastfeeding behavior (Johnson et al. 2015a, b).

\section{Purposive Sampling}

Purposive sampling methods were employed to select participants that might "provide rich, relevant, and diverse data pertinent to the research question" (Tong et al. 2007), p 352). Six focus groups of between five and eleven participants were held in the metro Detroit area. Eligible participants included either (1) mothers or expectant mothers who breastfed or planned to do so, or (2) those who did not to breastfeed, or (3) health professionals who supported mothers postpartum. Breastfeeding was defined as a baby receiving any breast milk.
Eligibility for the mothers or expectant mothers groups included self-identification as African American or black, pregnant, or with a child $<3$ years, and residency in southeast Michigan. Participants were recruited by distribution of flyers locally at local public health departments, several non-profit agencies, university community outreach office, schools, child care centers, housing sites, community churches, or hair salons.

Participants attended one of three categories of focus groups: exclusively for (1) professionals, or (2) women breastfeeding or planning to breastfeed, or (3) women not breastfeeding or planning to breastfeed. Two groups in each category were held. Focus groups were held at various locations and times convenient to most participants. The focus group participants are described in Table 2.

\section{Focus Groups}

A total of thirty-eight women participated in one of six focus groups in Detroit or Ypsilanti hereafter referred to as "Detroit focus group" or "Ypsilanti focus group". This included 29 pregnant or lactating women and nine health professionals (lactation consultants, peer breastfeeding counselors, midwives, WIC employees, or other health professionals supporting African American mothers). Focus groups with mothers took place at community centers and at a community room of a local museum. Focus group with professionals took place at the local public health department.

Focus groups were semi-structured and explored thoughts, perceptions, and behaviors related to interventions that support African American women's breastfeeding. Informed by grounded theory (Glaser and Strauss 2009), question guides were developed to enable consistency across groups (Kitzinger 1995). Guide questions are detailed in Table 1.

Groups were facilitated by the principal investigator (PI) - an experienced focus group facilitator who is an African American woman (with personal breast and formula feeding experience) and a Caucasian woman research assistant (RA).

Focus group discussions were audiotaped. The PI and the RA met immediately after each session to develop additional field notes.

\section{Analysis}

A grounded theory approach to data analysis and interpretation was used to generate themes from the range of participants' perceptions and experiences (Starks and Trinidad 2007). The authors used thematic analysis (AttrideStirling 2001) to inductively analyze focus group transcripts and field notes. Authors coded transcripts separately and differences in coding were resolved through discussion 
Table 1 Focus group guide and sample questions

Topic Prompt or question

1. Group introductions and infant feeding

(To mothers) a. As we go around to each of you, please clearly state your name, age of your child general thoughts (ren), or when your baby is due if you are pregnant

(To professionals) a. As we go around to each of you, please clearly state your name and the capacity in which you work with mother and how long you have worked in this capacity

a. What influences decisions to breastfeed babies? (Probe for specific examples that may influence mothers' breastfeeding decision: personal ideas, family, friends, media, personal experience, breastfeeding, educational material, etc.)

b. What is needed to support breastfeeding? (Probe for examples of things necessary for a mother to breastfeed: help from family, experience, education, support at work, etc.)

2. Maternity leave and return to work

c. How should this topic be approached in ways that best support breastfeeding mothers? (Probe for examples of strategies and ideas for addressing breastfeeding, maternity leave, and return to work: planning return to work, requesting more maternity leave, talking with work manager or boss, space and time to pump at work, etc.)

d. Who should be involved?

e. (If not mentioned ask) Should health professionals, family, friends or baby's daddy have input?

f. How can each of these people help support breastfeeding? (Probe for examples of others who should be involved: baby's dad, baby's grandmother, friend, healthcare professional including lactation consultant, peer counselor, obstetrician, mid-wife, pediatrician, primary care doctor, nurse, etc.)

3. Logistics of a breastfeeding support intervention program

a. If we were to design a program that effectively helps African American mothers start and continue breastfeeding, describe what it might look like

b. How would we go about it? (Probe for examples of the type of program that would work: group, individual counseling, telephone, internet, blogs, etc.)

c. When would it be best to offer this to mothers? (If not mentioned probe for examples of best times: evenings, daytime, before baby is born, after birth?)

d. Who might attend? (Probe for examples of who should be invited to attend: other moms with breastfeeding experience, dads, children, lactation consultant, etc.)

e. Where is the best location?

f. What are other practical concerns? (Probe for examples of things that program participants may need: childcare, transportation, electronic reminders, internet access, etc.)

4. Social support

a. Social support is thought to be important by some people. Others think that it can be unhelpful

b. Is there anything special or unique about support in the African American community that affects breastfeeding or bottle choices?

c. What type of support is most needed by African American women and their families in order to breastfeed? (Probe for examples of types of practical or other support: listening, advice, information, pumping space at work, break time to pump at work, space to pump in stores or restaurants, etc.)

d. From whom should the support come? (Probe for examples of formal or informal support: health professional, baby's dad, family, friends, etc.)

e. If not mentioned, prompt with: Should health professionals, family, friends or baby's daddy have input? (Remind participants that examples of health professionals might include lactation consultant, breastfeeding peer counselor, obstetrician, mid-wife, pediatrician, primary care doctor, nurse, etc.)

f. How can each of these people help support breastfeeding?

5. Additional Topics

a. Again, the purpose of this focus group is to gather information that could be used to develop and to test an intervention that addresses the barriers to breastfeeding for African American mothers

b. Are there any other topics or concerns we should address?

c. Is there anything we should have talked about but didn't?

d. (If no specific examples given prompt with) What issues or topics have we missed?

e. Once we have compiled findings, we'd like to have some participant volunteers to help us confirm findings. Please let us know if you might be interested before you leave 
Table 2 Demographics and characteristics of focus group participants

\begin{tabular}{|c|c|c|c|c|c|c|c|c|c|c|c|c|}
\hline \multirow{2}{*}{$\begin{array}{l}\text { Location/focus } \\
\text { group by infant } \\
\text { feeding type }\end{array}$} & \multicolumn{2}{|c|}{ Pregnant } & \multicolumn{2}{|c|}{ Race } & \multirow{2}{*}{$\begin{array}{l}\text { Age in } \\
\text { years } \\
\text { (mean) }\end{array}$} & \multicolumn{2}{|c|}{ Marital status } & \multirow{2}{*}{$\begin{array}{l}\text { Household } \\
\text { annual income } \\
\text { (range)* }\end{array}$} & \multicolumn{4}{|c|}{ Education completed } \\
\hline & Yes & No & $\mathrm{AA}$ & Caucasian & & Single & Married/partnered & & $<\mathrm{HS}$ & HS & $\begin{array}{l}\text { Some } \\
\text { college }\end{array}$ & $\begin{array}{l}\text { College } \\
\text { diploma }\end{array}$ \\
\hline $\begin{array}{l}\text { Yes } \mathrm{BF} \text { or } \\
\text { Planning to } \mathrm{BF} \\
(\mathrm{n}=5)\end{array}$ & 3 & 2 & 5 & 0 & 29 & 4 & 1 & $\$ 6200-21,000$ & 0 & 2 & 3 & 0 \\
\hline $\begin{array}{l}\text { Not BF nor } \\
\text { planning to } \mathrm{BF} \\
(\mathrm{n}=8)\end{array}$ & 0 & 8 & 8 & 0 & 27 & 8 & 0 & $\$ 1875-17,000$ & 0 & 3 & 5 & 0 \\
\hline $\begin{array}{l}\text { Health } \\
\text { Professional } \\
(\mathrm{n}=5)\end{array}$ & $\mathrm{n} / \mathrm{a}$ & & 1 & 4 & 44 & $\mathrm{n} / \mathrm{a}$ & & $\$ 24,400-39,1999$ & 0 & 0 & 2 & 3 \\
\hline $\begin{array}{l}\text { Detroit focus } \\
\text { group in } \\
\text { Southeastern } \\
\text { Michigan } \\
(\mathrm{n}=20)\end{array}$ & & & & & & & & & & & & \\
\hline $\begin{array}{l}\text { Yes } \mathrm{BF} \text { or } \\
\text { Planning to } \mathrm{BF} \\
(\mathrm{n}=11)\end{array}$ & 4 & 7 & 11 & 0 & 22 & 8 & 3 & $\$ 9545-24,817$ & 0 & 6 & 3 & 2 \\
\hline $\begin{array}{l}\text { Not BF nor } \\
\text { planning to BF } \\
(\mathrm{n}=5)\end{array}$ & 1 & 4 & 5 & 0 & 24 & 5 & 0 & $\$ 0-15,000$ & 2 & 1 & 2 & 0 \\
\hline $\begin{array}{l}\text { Health } \\
\text { Professional } \\
(\mathrm{n}=4)\end{array}$ & $\mathrm{n} / \mathrm{a}$ & & 4 & 0 & 39 & $\mathrm{n} / \mathrm{a}$ & & $\$ 31,000-45,000$ & 0 & 0 & 1 & 3 \\
\hline
\end{tabular}

* Household annual income is self-reported

and reference to the original transcripts. A content analysis framework was used to organize data into a structured format (Liamputtong 2005) which was then circulated as a draft to participants to verify interpretative accuracy. As a result of observations made during our thematic analysis, numerous major "metathemes" emerged and were highlighted in the larger study including lack of social support and non-breastfeeding friendly workplace environment (Johnson et al. 2015a). From these metathemes, emerged distinct sub-themes, one being the perceived impact of health professionals on breastfeeding intention and behavior derived from our close examination of individual experiential descriptions occurring commonly across focus groups (Tesch 1987). This last theme emerged as response to questions in the focus group guide, was also verified for interpretative accuracy by focus group participants, and is the focus of this paper. Results are organized first by major themes and then by highlighting similarities and differences that surfaced across groups within each theme.

\section{Results}

Themes from focus group discussions reflected both diversity and similarity in perspectives, as well as in social, and environmental risk factors. We found that participants in all groups overwhelmingly believed breastfeeding to be healthy and beneficial behavior for baby and mother postpartum. However, discussions similarly reflected that mothers often experienced personal adversity, unsupportive environments, (Conrad 2006; Smith-Gagen et al. 2014) and overwhelming mental and physical health problems (Mullings 2005) throughout pregnancy and postpartum. Moreover, participants from all groups frequently described poor health conditions as prohibitive to breastfeeding and sometimes described having little or no support from personal and healthcare environments in addressing breastfeeding barriers. Thematic differences also emerged from focus groups across geographic areas and infant feeding methods. 


\section{Participants Believe Breastfeeding is Healthy but Describe Poor Health as a Barrier}

Participants generally agreed that breastfeeding is the healthier infant feeding method:

But, with the breastfeeding like, a lot of people just want it because it helps release like, you know helps your belly go down ...

(mother in Detroit focus group who formula fed)

In the beginning I wanted to breastfeed because I felt like this is the healthiest thing (for) his immune system (and) is gonna be great...

(mother in Ypsilanti focus group who breastfed)

\section{Stress, Physical and Mental Health Challenges}

Breastfeeding and formula feeding mothers similarly described physical and mental health challenges and personal frustrations that overshadowed capacity and opportunity to breastfeed. Breastfeeding was negatively influenced by the stress of managing competing life demands with little resources and support during the postpartum period. Some mothers who indicated at prescreen that they had "breastfed" their baby commonly switched to formula feeding after encountering challenges postpartum.

I tried breastfeeding well I tried pumping but ... it wouldn't come down so I used formula. But also my son was sick so he had to use the special kind of formula ... I attempted ... it just didn't work.

(Mother in Ypsilanti focus group who breastfed)

I had my mastectomy with me so I can't. They took all my milk away.

(Mother from Ypsilanti focus group who formula fed)

Is going to then lead to stress in some sort of way because she's feeling like she doesn't have the time for this person but she knows she has to spilt and divide but how do you do? How do you organize? (Mother from Ypsilanti focus group who formula fed)

While all participants shared that stress or poor mental health threatened breastfeeding, formula feeding mothers from the Detroit focus group, particularly, were far more likely to describe poor mental health, stress, and infant mortality as major breastfeeding barriers that required attention before breastfeeding could be discussed.

You know it is quite stressful trying to breastfeed because they (babies) ... they do cluster feeding ... and they just crying all hours.

(Mother in Ypsilanti focus group who breastfed)
I got so frustrated ... the baby kept crying like he wasn't getting enough. So I started crying. Because I was like I can't feed the baby. Making you feel better just give him a bottle too.

(mother in Ypsilanti focus group who breastfed then bottle fed)

Depression for me. Because that's like one of the biggest things when you have kids. (another mother: especially when it's your first time)... when I had my daughter, my mother... died.. two weeks before, it made it a lot harder ..., so it's like the depression then it's like separates (you) from the baby and everybody else 'cause you just wanna be alone. So yeah, that's probably like one of the reasons why I didn't breastfeed.

(mother from Detroit focus group who formula fed her baby)

Health professionals in the Detroit focus group similarly highlighted stress and poor mental health as major breastfeeding barriers and expressed frustration around ways to effectively support mothers around these issues during the postpartum. One healthcare professional from the Detroit focus group added:

(A) Lot of mental barriers... and these are young women. And you can see somebody you can have a conversation and go God something is wrong here. What's the point of giving you all the education and I know you are not going to retain it because you got other issues going on so it has to be addressed? You can't overlook any barriers they have. We may come in with our own agenda and how wonderful it (breastfeeding) is but mentally (they) got something going on or physically.

\section{Breastfeeding Support From Healthcare Professionals?}

Breastfeeding mothers in both cities were more likely to describe unsupportive physical and social environments both public and private (Johnson et al. 2015a). Discussions often suggested that mothers felt healthcare providers sometimes discouraged breastfeeding, and that they lacked information or support from their healthcare providers. This was especially true in the Detroit focus group of breastfeeding mothers. One mother describes being told that she could not breastfeed in her doctor's waiting room:

Like when I go to my doctor's office I complain so many times. Cause they told me, when the lobby filled up, 'it's too small of an area, you shouldn't be feeding your baby out here'. 
(Mother in Detroit focus group who breastfed)

Another mother describes how after experiencing a health crisis post birth, her health provider failed to inform her of ways she might continue breastfeeding:

I had a blood pressure spike issue come about and the medicine I was on, my doctor just basically told me I should stop nursing. I didn't really know about the pumping and dumping kind of thing and I stopped and my milk dries up. My intention was to nurse for like over a year until she weaned herself but my doctor who was an OBGYN wasn't baby friendly and just basically suggested me to stop nursing because of this. The drug was a strong drug and would have been excreted in my milk, I get that. But why not offer me a suggestion, I've been nursing for 3 months.

(Mother from Detroit focus group who breastfed)

\section{Healthcare Providers and Trust}

Mothers expressed mistrust about information they received from healthcare professionals and expressed that support was sometimes unavailable in the way they most needed it.

I know some hospitals pretend to be baby friendly but a lot of times that's not the forefront. You see all this foreign stuff in the room, they force it on you, you might state you wanna breast feed...(but), the baby's in the nursery and they wanna give your baby formula when you're sleep or things like that. (mother from Detroit focus group who breastfed)

... it came to one point where he wasn't even latching on at all. He wasn't eating for 12 hours. I was freaking out ... I had no one to help me. So I had to just figure it out. Me being a new mom. ... I started getting the formula when I decided ... to get a bottle. Because I didn't know what I had to do. ... I felt like doctors could only tell you so much really.

(mother in Detroit focus group who breastfed)

\section{Differences in Types of Breastfeeding Support}

When asked what types of interventions they feel might be most supportive of breastfeeding, mothers and health professionals, generally said that hospitals need to educate more and to show more clear and deliberate support of breastfeeding in place of behavior that seemed to discourage breastfeeding:

...that the hospitals need to come in and give the benefits more than they do I think that it's more doctors' offices encouraging, encouraging breastfeeding. (mother in Detroit focus group who breastfed)

However, ideas from the health care professionals in the Ypsilanti focus group were remarkably different from suggestions offered by their counterparts in the Detroit focus group. Health professionals in the Ypsilanti focus group appeared hopeful and suggested that professional education and technical support postnatally could help to counter breastfeeding barriers they saw among the mothers they served:

I think that everybody who's breastfeeding or has desire to breastfeed ... could make an appointment ... with a lactation consultant ... (on same) day that they go to the pediatricians office, they see somebody, (who) watches the feed, answers their questions, gives them anticipatory guidance because it's that time between discharge from the hospital and they have that first pediatricians office and when they go back at 2 weeks when like everything falls apart ... (health professional from Ypsilanti focus group)

Conversely, health professionals in the Detroit focus group seemed overwhelmed by the complexity of social, personal, and health problems they witnessed in mothers. These health professionals spent a significant amount of time talking about the experiences of working with several mothers plagued by poverty or poor health and shared they thought mothers first needed help with addressing these issues before they could discuss breastfeeding:

(I've heard mothers say...) I need a refrigerator. I need a bed. I am sleeping on the floor... So you that's where I said you have to kinda have to knock down some of the barriers before you can (talk about or breastfeed).

Similarly, mothers differed in their perspective. Some mothers expressed a need for a comprehensive healthcare team to help manage frequently experienced chronic negative health, medication use, and breastfeeding.

through my pregnancy, my blood pressure's been very, very good, so towards the end ... it's rising a little bit, ... once I have the baby is it gonna go skyrocketing or is it gonna stay at this level and if so, do I take medicine? ... what do I do 'cause I don't wanna pass the medicine onto the baby, what what do I do? And then I have, you know, issues with like anxiety, so I was taking pills for that.

(mother from Ypsilanti focus group who breastfed)

... the physician and ... the lactation consultant should be able to partner...before you get your checkup or after, you have a consultant to come in .... and talk to you about ways you can breastfeed or ... try to 
get you to breastfeed and ... to help you with your anxiety or your diabetes ... I think it's a different way to go about it. ... it should be required

(mother from Ypsilanti focus group who planned to breastfeed)

Health professionals in both cities acknowledged that available lactation programs are often unable to meet mothers' needs and fall short of delivering culturally-relevant breastfeeding support they need to initiate or to continue breastfeeding. Professionals shared they sometimes weren't sure what mothers needed; continuity in care, education, and cultural fit were commonly discussed. However, cultural fit only represents a part of what lowincome, minority women need to breastfeed (Labbok 2013). Information shared in discussion suggests that because breastfeeding rates decline rapidly after mothers return to work and other major life duties, they also need support that extends beyond the hospital environment and that includes peer support (Bentley et al. 2003).

\section{Culturally Relevant Support at Multiple Levels is Needed}

Ideas shared by participants reflect that African American women's breastfeeding experiences are contextualized by their unique socio-historical reproductive experiences. Health professionals and mothers across all focus groups expressed an interest in finding practical, communitybreastfeeding support that includes peer, group, individual, family, and community support that many current lactation support programs don't offer. However, participants from the Detroit focus group, especially, voiced a need for support pre-natally as well as post-natally that is informed by the unique socio-historical context of African American women's lives:

... working with one of our agencies... I learned that ...(during) slavery... (slave) moms were made to breastfeed ...The master's child, ...(they) couldn't nourish (their)own children ... it became a generational thing ... so it became a norm.

(health professional in Detroit focus group)

La Leche League... have not been able to get African American moms to come to meetings. So that, that model doesn't work for them. But maybe their own kind of model where they are getting together ... (for) information and support and knowledge before they give birth and through birth and afterwards and just having somewhere where they can talk to each other, support each other.

(health professional in Ypsilanti focus group) having (a way) that we can come together and help to educate one another and support each other .... having the support, the support groups and being able to make a phone call and somebody come to the house ... it's more on our level too, ... 'cause sometimes trying to make it to that hospital or ... 'cause you may not be comfortable yet with the four people in the room, so if you have it with just one person coming to your house, that's, you know, really beneficial

(mother in Ypsilanti focus group who breastfed)

\section{Discussion}

Several narratives emerged from our focus group discussions. First, participants generally agreed that despite knowing the health benefits of breastfeeding, significant barriers threatened successful breastfeeding initiation or breastfeeding duration, current breastfeeding support was inadequate, they also expressed divergent ideas about what specific support is needed. Breastfeeding was frequently compromised by multiple factors pre- and post-natally including mothers' life demands, chronic health problems, resource-poor environments, lack of confidence, and perceived lack of support. Mothers and practitioners often shared that African American mothers want communitybased breastfeeding support led by other African American mothers who can relate to their unique cultural and social experiences and who can assist with negotiating the structural and environmental challenges of breastfeeding in under-resourced conditions. Participants felt that healthcare providers they interfaced with often did not provide this support. As expected, mothers who had given birth shared more information and ideas about breastfeeding challenges related to their post-delivery experiences with health professionals and others.

\section{Breastfeeding Requires Opportunity, Confidence, and Culturally Appropriate Support}

Breastfeeding self-efficacy is inextricably linked to breastfeeding initiation and duration (Lee-Dennis 2006). While BFHI interventions have shown some success with building breastfeeding self-efficacy and exclusive breastfeeding rates post-discharge, BFHI-practicing hospitals are typically not located near African American communities. Another likely factor is the significant racial inequity in access to the International Board Certified Lactation Consultant (IBCLC) credentials. A 2011 national survey of insurance reimbursement revealed racial demographic breakdown of US IBCLC reflects $87 \%$ as non-Hispanic 
white, $1.6 \%$ non-Hispanic black, $4.7 \%$ Hispanic, $1.4 \%$ Asian/Pacific Islander, $0.8 \%$ American Indian/Native Alaskan, $0.7 \%$ mixed race, and $3.7 \%$ other (Chetwynd et al. 2013). The majority of IBCLC professionals are white, Caucasian women who may lack cultural insight when working with a largely African American community. Increasing recruitment of qualified African American as peer counselors might also help and promote greater use of local, African American peers as advisers. While breastfeeding support from doulas (Mottl-Santiago et al. 2008), midwives, and breastfeeding peer counselors (Chapman et al. 2010) may have a positive impact on breastfeeding behavior among African American women, credentials and availability vary for these within the hospital and early postpartum environment. Enduring racial and ethnic disparities in breastfeeding behavior are systemic issues and require a multilevel systems intervention approach (Johnson et al. 2015b). This idea is reflected in sentiment shared by mothers who voiced an interest in having consistent reliable support from the health professional level (Spencer 2008) as well as more proximal support from fathers, peers, family, and community communities as other research suggest (Derige 2013; Green 2010; Sikorski et al. 2003).

\section{Does Cultural Bias Exist?}

Evidence suggests that racial/ethnic disparities in breastfeeding may also be due, in part, to institutional systems or practices which include biased (unintentional and intentional) or unconsciously prejudiced care on the part of professional breastfeeding support (Mojab 2015). Views expressed by participants reflect low breastfeeding success expectations possibly precipitated by the lack of tangible and other support from providers. Hospitals and healthcare providers may have lower expectations for patients in socially or economically disadvantaged positions (based on race/ethnicity, income, education, or social class) which in turn influence African American mothers' poor breastfeeding expectations and outcomes (Centers for Disease Control and Prevention 2014; Mondloch et al. 2001). Further discussion and research is needed to explore implicit bias and its impact on African American breastfeeding mothers. Training should include an environmental scan that systematically surveys and evaluates information to identify opportunities and barriers to evaluate policies or institutional systems that allow discriminatory practices (Mojab 2015).

\section{Bridge Hospital-Community Breastfeeding Support}

Third, and final, more work is needed to enhance hospital-community partnerships that introduce social supports for breastfeeding mothers prior to delivery and close the gap between hospital and community support. Hospital-community partnerships could help create seamless breastfeeding support that blends professional prenatal and pregnancy breastfeeding education on benefits, work return plans, etc., with professional and personal community supports who help mothers continue to breastfeed. Community support is one key factor for sustaining any short term breastfeeding gains achieved in BFHI institutions (Pérez-Escamilla et al. 2016) as well as in other hospital environments. Mothers should be introduced to community supports to build relationships prior to delivering their baby, proactively planning for the postpartum period.

\section{Study Limitations}

This study includes several limitations. First the number of focus group participants who were health professionals is small $(\mathrm{n}=9)$ and were all non-physicians. Several potential healthcare professionals cited busy schedules and scheduling conflicts. Additionally, attempts were made to recruit physicians for the study with little results. Two physicians completed pre-screening but neither participated due to last minute scheduling conflict with one and a no-show with the other. The absence of physicians' perspective represents a critical void. Further, it highlights an important opportunity to engage physicians in the breastfeeding discourse in ways that pinpoint the root of patientphysician issues around breastfeeding and bridge the healthcare and personal environment divide. Second, there are several limitations to generalizability and design. This is a qualitative and exploratory study with a relatively small sample of predominantly low-income African American women in an urban Midwestern setting, thus results are not generalizable to all populations of African American mothers and healthcare professionals. Third, no African American lactation consultants participated in this study which highlight the lack of culturally-informed breastfeeding role models need for African American women and a missing cultural perspective. Fourth, focus group methodology is based on individuals' perspectives and personal experiences, thus dependent on participant selection (Krueger and Casey 2000).

\section{Conclusions for Practice}

We found that perceptions and expectations expressed in the narratives vary in terms of prioritization but explicitly address that African American mothers have diverse breastfeeding intervention needs and expectations. While 
health professionals might be aware of these needs they are challenged with addressing them in consistent and standardized manner. Addressing African American mothers breastfeeding support needs require a contextualized approach that combines credible, professional knowledge, expertise, and conscience cultural awareness, with proximal interpersonal social support within a continuum of care from pregnancy thru postpartum. Findings suggest training ideas and consideration for increasing the diversity and equity of available breastfeeding support resources for African American women.

Acknowledgments This study was supported by Grant Number 2UL1TR000433 from the National Center for Advancing Translational Sciences (NCATS). The content is solely the responsibility of the authors and does not necessarily represent the official views of NCATS or the National Institutes of Health. This study was supported by the Department of Psychiatry, Women and Infants Mental Health Program, and by the Program for Multicultural Health both at the University of Michigan Health System. We gratefully thank the women who participated in our study.

\section{Compliance with Ethical Standards}

Conflict of interest The authors declare that they have no conflict of interest.

\section{References}

Attride-Stirling, J. (2001). Thematic networks: An analytic tool for qualitative research. Qualitative Research, 1(3), 385-405.

Bartick, M., \& Reinhold, A. (2010). The burden of suboptimal breastfeeding in the United States: A pediatric cost analysis. Pediatrics, 125(5), e1048-e1056. doi:10.1542/peds.2009-1616.

Bentley, M. E., Dee, D. L., \& Jensen, J. L. (2003). Symposium: Beliefs, power and the state of nutrition: Integrating social science perspectives in nutrition Interventions Breastfeeding among low income, African-American women: Power, beliefs and decision making 1, 2. American Society for Nutritional Sciences, 3, 305-309.

Centers for Disease Control and Prevention. (2014). Racial disparities in maternity care PRACTICES that support breastfeeding. MMWR, 63(33), 725-728.

Centers for Disease Control and Prevention, N. I. S. (2015). Rates of any and exclusive breastfeeding by socio-demographics among children born in 2012. http://www.cdc.gov/breastfeeding/data/ NIS data/.

Chapman, D., Morel, K., Anderson, A. K., Damio, G., \& PerezEscamila, R. (2010). Review: Breastfeeding peer counseling: from efficacy through scale-up. Journal of Human Lactation., 26(3), 314-326.

Chetwynd, E., Meyer, A.-M., Stuebe, A., Costello, R., \& Labbok, M. (2013). Recognition of International Board Certified Lactation Consultants by health insurance providers in the United States: Results of a National Survey of Lactation Consultants. Journal of Human Lactation, 29(4), 517-526. doi:10.1177/ 0890334413499974.

Conrad, C. (2006). African Americans and high-tech jobs: Trends and disparities in 25 cities. Washington, DC: The Joint Center for Political and Economic Studies.
Demirci, J. R., Bogen, D. L., Holland, C., Tarr, J. A., Rubio, D., Li, J., et al. (2013). Characteristics of breastfeeding discussions at the initial prenatal visit. Obstetrics and Gynecology, 122(6), $1263-1270$.

Derige, D. N. (2013). Growing a first food movement. Breastfeeding Medicine, 8(5), 433-434. doi:10.1089/bfm.2013.0073.

Ehrenreich, N., \& Siebrase, J. (2014). Breastfeeding on a Nickel and a Dime: Why the affordable care act's nursing mothers amendment won't help low-wage workers. Michigan Journal of Race \& Law, 20, 65 .

Gayle Shipp, M. S., \& Michigan, C. L. S. (2015). Supporting the Breastfeeding Mom. Michigan Department Health and Human. https://events.mphi.org/wp-content/uploads/2015/04/603-Waysto-support-breastfeeding-mom.pdf.

Glaser, B. G., \& Strauss, A. L. (2009). The discovery of grounded theory: Strategies for qualitative research. Piscataway, NJ: Aldine Transaction Publishers at Rutgers-The State University.

Green, K. E. (2010). Black mothers' breastfeeding club: Community outreach and active support. Breastfeeding Medicine, 5(5), 221-222. doi:10.1089/bfm.2010.0031.

Gross, T. T., Powell, R., Anderson, A. K., Hall, J., Davis, M., \& Hilyard, K. (2014). WIC peer counselors' perceptions of breastfeeding in African American women with lower incomes. Journal of Human Lactation, 31(1), 99-110.

Horta, B. L., \& Victora, C. G. (2013). Long-term health effects of breastfeeding. World Health Organization, 129(8-9), 57-64. http://www.ncbi.nlm.nih.gov/pubmed/20960419.

Johnson, A. M. (2010). Analyzing the social context of disparate breastfeeding outcomes through intersectional paradigms: Lessons learned from a qualitative study of African American mothers. Dissertation Abstracts International Section A: Humanities and Social Sciences, 72(1-A), 380. http://search.ebscohost. com/login.aspx?direct=true \&db=psyh\&AN=2011-99130-070\&si te $=$ ehost-live.

Johnson, A. M., Kirk, R., \& Muzik, M. (2015a). Overcoming workplace barriers: A Focus Group Study exploring African American mothers' needs for workplace breastfeeding support. Journal of Human Lactation, 31(3), 425-433. doi:10.1177/ 0890334415573001.

Johnson, A., Kirk, R., Rosenblum, K. L., \& Muzik, M. (2015b). Enhancing breastfeeding rates among African American women: A systematic review of current psychosocial interventions. Breastfeeding Medicine, 10(1), 45-62. doi:10.1089/bfm.2014. 0023.

Jones, K. M., Power, M. L., Queenan, J. T., \& Schulkin, J. (2015). Racial and ethnic disparities in breastfeeding. Breastfeeding Medicine, 10(4), 186-196.

Kitzinger, J. (1995). Qualitative research. Introducing focus groups. BMJ (Clinical Research Ed.), 311(7000), 299-302. doi:10.1136/ bmj.311.7000.299.

Kramer, M. S., Fombonne, E., Igumnov, S., Vanilovich, I., Matush, L., Mironova, E., et al. (2008). Effects of prolonged and exclusive breastfeeding on child behavior and maternal adjustment: Evidence from a large. Randomized Trial. Pediatrics, 121(3), e435-e440. doi:10.1542/peds.2007-1248.

Krueger, R., \& Casey, M. (2000). Focus Groups: A practical guide for applied research (3rd ed.). Thousand Oaks, CA: SAGE.

Labbok, M. H. (2013). Breastfeeding: Population-based perspectives. Pediatric Clinics of North America, 60(1), 11-30. doi:10.1016/j. pcl.2012.09.011.

Lee-Dennis, C. (2006). Idneitfying predictors of breastfeeding Selfefficacy in the immediate postpartum period. Research in Nursing \& Health, 29(4), 256-268.

Li, R., Hsia, J., Fridinger, F., Hussain, A., Benton-Davis, S., \& Grummer-Strawn, L. (2004). Public beliefs about breastfeeding 
policies in various settings. Journal of the American Dietetic Association, 104(7), 1162-1168.

Liamputtong, P., \& Ezzy, D. (2005). Qualitative research methods (p. 404). Melbourne, VIC: Oxford University Press.

McCarter-Spaulding, D., Lucas, J., \& Gore, R. (2011). Employment and breastfeeding outcomes in a sample of black women in the United States. Journal of National Black Nurses Association, 22, $38-45$.

Medicine, B. (ABM). (2013). Black Mothers Breastfeeding Association receives grant to help eradicate breastfeeding disparities. Retrieved August 10, 2014, from https://bfmed.wordpress.com/ 2013/06/10/black-mothers-breastfeeding-association-receivesgrant-to-help-eradicate-racial-breastfeeding-disparities/.

Merewood, A., Mehta, S. D., Chamberlain, L. B., Philipp, B. L., \& Bauchner, H. (2005). Breastfeeding rates in US baby-friendly hospitals: Results of a national survey. Pediatrics, 116(3), 628-634.

Mojab, C. G. (2015). Pandora's box is already open: Answering the ongoing call to dismantle institutional oppression in the field of breastfeeding. Journal of Human Lactation, 31(1), 32-35. doi: $10.1177 / 0890334414554261$.

Mondloch, M. V., Cole, D. C., \& Frank, J. W. (2001). Does how you do depend on how you think you'll do? A systematic review of the evidence for a relation between patients' recovery expectations and health outcomes. CMAJ, 165(2), 174-179.

Mottl-Santiago, J., Walker, C., Ewan, J., Vragovic, O., Winder, S., \& Stubblefied, P. (2008). A hospital-based doula program and childbirth outcomesin an urban, multicultural setting. Maternal and Child Health Journal, 12(3), 372-377.

Mullings, L. (2005). Resistance and resilience: The sojourner syndrome and the social context of reproduction in cenral harlem. Transforming Anthropology, 13(2), 79-91.

Organization, W. H. (2001). The optimal duration of exclusive breastfeeding: Report of an expert consultation. Retrieved October 13, 2015, from http://www.who.int/nutrition/publica tions/infantfeeding/WHO_NHD_01.09/en/.

Pérez-Escamilla, R., \& Chapman, D. J. (2012). Breastfeeding protection, promotion, and support in the United States A Time to Nudge, a Time to Measure. Journal of Human Lactation, $28(2), 118-121$.

Pérez-Escamilla, R., Martinez, J. L., Segura-Pérez, S. (2016). Impact of the Baby-friendly Hospital Initiative on breastfeeding and child health outcomes: A systematic review. Maternal and Child Nutrition, 12(3), 402-417.

Perez-Escamilla, R., \& Sellen, D. (2015). Equity in breastfeeding: Where do we go from here? Journal of Human Lactation, 31(1), 12-14. doi:10.1177/0890334414561062.

Porr, Carolyn, Drummond, Jane, \& Richter, S. (2006). Health Literacy as an empowerment tool for low-income mothers. Family \& Community Health: The Journal of Health Promotion and Maintenance, 29(4), 328-335.
Ramey, S. L., Schafer, P., DeClerque, J. L., Lanzi, R. G., Hobel, C., Shalowitz, M., et al. (2015). The preconception stress and resiliency pathways model: A multi-level framework on maternal, paternal, and child health disparities derived by communitybased participatory research. Maternal and Child Health Journal, 19(4), 707-719. doi:10.1007/s10995-014-1581-1.

Saadeh, R. J. (2012). The baby-friendly hospital initiative 20 years on: facts, progress, and the way forward. Journal Human Lactation, 28(3), 272-275.

Saadeh, R., \& Casanovas, C. (2009). Implementing and revitalizing the baby-friendly hospital initiative. Food and Nutrition Bulletin, 30(2Suppl2), S225-S229.

Sikorski, J., Renfrew, M. J., Pindoria, S., \& Wade, A. (2003). Support for breastfeeding mothers: A systematic review. Paediatric and Perinatal Epidemiology, 17(4), 407-417.

Smith-Gagen, J., Hollen, R., Walker, M., Cook, D. M., \& Yang, W. (2014). Breastfeeding laws and breastfeeding practices by race and ethnicity. Women's Health Issues, 24(1), e11-e19. doi:10. 1016/j.whi.2013.11.001.

Spencer, R. L. (2008). Research methodologies to investigate the experience of breastfeeding: A discussion paper. International Journal of Nursing Studies, 45(12), 1823-1830. doi:10.1016/j. ijnurstu.2008.04.008.

Spencer, B. S., \& Grassley, J. S. (2012). African American women and breastfeeding: An integrative literature review. Health Care for Women International, 9332(April 2013),. doi:10.1080/ 07399332.2012 .684813$.

Starks, H., \& Trinidad, S. B. (2007). Choose your method: a comparison of phenomenology, discourse analysis, and grounded theory. Qualitative Health Research, 17(10), 1372-1380. doi:10.1177/1049732307307031.

Stuebe, A. (2009). The risks of not breastfeeding for mothers and infants. Reviews in Obstetrics and Gynecology, 2(4), 222-231.

Tesch, R. (1987). Emerging themes: the researcher's experience. Phenomenology \& Pedagogy, 5(3), 230-241.

Tiedje, L. B., Schiffman, R., Omar, M., Wright, J., Buzzitta, C., McCann, A., et al. (2002). An ecological approach to breastfeeding. MCN: The American Journal of Maternal/Child Nursing, 27(3), 154-161.

Tong, A., Sainsbury, P., \& Craig, J. (2007). Consolidated criteria for reporting qualitative research (COREQ): A 32-item checklist for interviews and focus groups. International Journal for Quality in Health Care, 19(6), 349-357. doi:10.1093/intqhe/mzm042.

USA, B. F. (2012). The ten steps to successful breastfeeding. Retrieved October 13, 2015, from http://www.babyfriendlyusa. org/about-us/baby-friendly-hospital-initiative/the-ten-steps.

Who/Unicef. (2012). Global Nutrion Target 2025.Breastfeeding Policy Brief.WHO/MNH/NHD 14.7, 8. 